\title{
Differential expression of two glucocorticoid receptors in seabass (teleost fish) head kidney after exogeneous cortisol inoculation
}

\author{
Mirella Vazzana, Aiti Vizzini, Maria Antonietta Sanfratello, Monica Celi, \\ Giuseppina Salerno, Nicolò Parrinello*
}

Laboratory of Marine Immunobiology, Department of Animal Biology, University of Palermo, Via Archirafi, 18 Palermo, Italy

\section{A R T I C L E I N F O}

\section{Article history:}

Received 23 November 2009

Received in revised form 30 April 2010

Accepted 3 May 2010

Available online 10 May 2010

\section{Keywords:}

Dicentrarchus labrax

Cortisol

Glucocorticoid receptor

Real-time PCR

\begin{abstract}
A B S T R A C T
Stressful conditions include a prompt release of corticosteroid hormones which can mediate gene expression through glucocorticoid receptors (GR). Since two seabass (Dicentrarchus labrax) GRs have been cloned and sequenced from peritoneal cavity cells (DIGR1) and liver (DIGR2), a comparative amino acid sequence analysis that included Haplochromis burtoni HbGRs, was carried out and homologies disclosed. The DIGR1 and DIGR2 deduced aminoacid sequences showed 61\% identity (I) and 70\% similarity (S). Moreover, DIGR2 was similar to HbGR2b (69\% I, 73\% S), and the DIGR1 to HbGR1 (72\% I, 78\% S). In addition, we examined the expression of the DIGRs after exogeneous cortisol inoculation into the peritoneal cavity, mimicking stress effects. At various times after the administration ( $3 \mathrm{~h}, 24 \mathrm{~h}, 1$ week), gene expressions was evaluated in head kidney by real-time PCR. In addition, immunoblotting and densitometry analyses were performed with antiDIGR1 antibodies. Although sea bass head kidney expressed both DIGR1 and DIGR2 they were differentially modulated by intraperitoneal implant of exogeneous cortisol.
\end{abstract}

(c) 2010 Elsevier Inc. All rights reserved.

\section{Introduction}

Glucocorticoids (GCs), including cortisol and corticosterone, are secreted by the cortex of the adrenal gland and exert a pivotal control role in vertebrate physiology. GCs and the nuclear glucocorticoid receptors (GRs) are involved in the regulation of cell growth, bone density, metabolism and cardiovascular system, and influence behavior (Charmandari et al., 2005). In addition, elevated GCs levels following stressful conditions exert immunosuppressive effects (Elenkov, 2004). The GR genes are present among all classes of vertebrates indicating strong evolutionary pressure and gene conservation (Stolte et al., 2006).

In fish, cortisol is the predominant glucocorticoid; it is synthesized by interrenal cells of the head kidney and regulates osmolarity, metabolism and immune responses (Wendelaar Bonga, 1997; Mommsen et al., 1999; Vazzana et al., 2002; Vizzini et al., 2007). Moreover, it is a key mediator of stress-associated responses (Vijayan et al., 1997; Mommsen et al., 1999; Sapolsky et al., 2000). Hyperglycemia (Pottinger, 1998; Vazzana et al., 2002), variations in plasma osmolarity (Mugnier et al., 1998) and lactate levels are effects of enhanced cortisol (Milligan and Girard, 1993; Pottinger, 1998), and considered as stress indicators (Barton et al., 2002). Following cortisol binding, fish intracellular GRs exert their activity on the expression of

\footnotetext{
* Corresponding author. Tel.: + 39091 6230150; fax: + 390916230144. E-mail address: nicpar@unipa.it (N. Parrinello).
}

the target genes by ligand-dependent transcription factor (Beato et al., 1996; Prunet et al., 2006; Bury and Sturm, 2007).

A GR phylogenetic tree, distinguishes a cluster of tetrapod GRs and a cluster of the teleost fish GRs (Stolte et al., 2006). The fish GR cluster is subdivided into two different clades representing two different GR genes. Duplicate GR genes have been found in salmonids (Bury et al., 2003; Ducouret et al., 1995) and cichlids including Burtons' mouthbrooder (HbGRs) (Greenwood et al., 2003). GRs display high aminoacid sequence identity especially in the C-terminal part. Finally, tissue GR analyses revealed differential distribution and expression levels of duplicate genes (Bury et al., 2003; Greenwood et al., 2003; Ducouret et al., 1995).

In sea bass (Dicentrarchus labrax), two distinct GRs have been sequenced: the DIGR1 from the peritoneal cavity cells (Vizzini et al., 2007) and a GR (here named DIGR2) from the liver (Terova et al., 2005). DIGR1 cDNA disclosed four functional domains, for transcriptional activation, DNA-binding, nuclear localization, and hormonebinding; it is expressed in macrophages and neutrophils from the peritoneal cavity (Vizzini et al., 2007), in the head kidney, spleen, gill, intestine, heart and liver tissues (Vazzana et al., 2008). Although stress-associated increased plasma cortisol can modify the GR gene expression, contrasting results on gene regulation have been reported (Terova et al., 2005; Vijayan et al., 2003; Sathiyaa and Vijayan, 2003; Takahashi et al., 2006). In the present paper, DIGR1, DIGR2 and HbGR sequences were compared and homology levels disclosed. Furthermore, since the differential expression of the duplicate GR genes suggests that they could regulate different functions, the DIGR1 and 
DIGR2 expressions following a cortisol stimulus were examined. Our results show that the head kidney, the main fish hemopoietic organ involved in immune responses, expresses both DIGR1 and DIGR2 differentially modulated by intraperitoneal implant of exogeneous cortisol that mimics stress effects.

\section{Materials and methods}

\subsection{Animals and experimental design}

Sea bass (D. labrax, Perciformes, Moronidae) (200-250 g) were provided by ECO-ITTICA (Marsala, TP) fish farm. Three distinct fish groups were arranged in separated $100 \mathrm{~L}$ tanks with continuously flowing aerated sea water $\left(18{ }^{\circ} \mathrm{C}\right)$ and acclimated for at least two weeks before starting the experiments. Each group contained 15 individuals/experiment for each tank, and a total of 45 fish was examined. The groups were designed as untreated (Untr.), vehicletreated (I) and cortisol-treated (II).

To avoid circadian effects, fish sampling was carried out at a set up time in the morning. Fish were anaesthetized with $0.05 \% 3-$ aminobenzoic acid ethyl ester (Sigma-Aldrich, Germany) in seawater. Intraperitoneal implants of $20 \mathrm{mg}$ cortisol kg ${ }^{-1}$ body mass in $2.5 \mathrm{~mL}$ medium (ethanol/1:4 diluted Hanks balanced salt solution, v/v) (vehicle) were given to each specimen from group II. Fish from group I (control) were treated with the vehicle alone (sham fish). Five fish from I and II groups were sampled at $3 \mathrm{~h}, 24 \mathrm{~h}$ and 1 week after the inoculation, and five fish were taken at the same time/point from the untreated group (Untr.). After anesthesia, bleeding fish were killed with a lethal dose of $0.1 \% 3$-aminobenzoic acidethyl ester, and the head kidney was excised. To prepare plasma, the blood was withdrawn from the heart into heparinized sterile plastic syringes, and centrifuged at $800 \times \mathrm{g}$ for $10 \mathrm{~min}$ at $4{ }^{\circ} \mathrm{C}$. The excised head kidney was divided in two parts, one half was placed in RNA later (Ambion) for mRNA analysis, and the second part was stored at $-80{ }^{\circ} \mathrm{C}$ for protein analysis.

\subsection{Plasma analysis}

Plasma cortisol was measured by using the ELISA method according to the manufacturer instructions (Globe diagnostics S.r.l., Italy). This test is based on competition enzyme immunoassay into microwells coated with specific anti-cortisol-antibodies simultaneously with conjugated cortisol-peroxidase. After washing, the remaining enzymatic activity bound to the microwell surface was detected and quantified by adding a chromogen-substrate mixture and stop solution. Optical density was recorded at $450 \mathrm{~nm}$, and cortisol concentration was calculated based on a series of standards.

The glucose and lactate levels were recorded by Accutrend GC kit (Boehringer Mannheim) and Lactate Dry-Fast kit (Sentinel diagnostics, Italy) respectively. To check for osmolarity, a freezing-point depression osmometer (Roebling) was used.

\subsection{Total RNA extraction and cDNA synthesis}

Total RNA was isolated from the head kidney, by using a RNAqueous ${ }^{\mathrm{TM}}$-Midi Kit purification system (Ambion), and reversetranscribed by the Kit Ready to $\mathrm{Go}^{\mathrm{TM}} \mathrm{T}$-primed first-strand using random primers (Amersham-Pharmacia Biotech, USA).

\subsection{Real-time PCR analysis}

Tissue expression of DlGR genes (DlGR1 Accession Number AY619996; DIGR2 (liver GR) Accession Number AY549305) was detected by real-time PCR by using the Taqman method. Primers and hybridization probes were designed using primer express software V.0 and synthesized commercially (Applied Biosystem, Foster City, CA,
USA). The Taqman probe sequence contained a 5'-FAM fluorophore and 3' MGB quencher for target genes (DlGR1 and DlGR2) and 5'-VIC fluorophore and 3' MGB quencher for the housekeeping gene ( $D$. labrax actin Accession Number AY148350). Real-time PCR analysis was performed using the Applied Biosystem 7500 real-time PCR system. Tissue expression was performed in a $25 \mu \mathrm{L}$ PCR reaction containing $2 \mu \mathrm{L}$ cDNA converted from $250 \mathrm{ng}$ of total RNA, $100 \mathrm{nM}$ of DIGR1 probe (TCGGTCTGGGCTGGCGGTCT), $400 \mathrm{nM}$ of DIGR1 forward (5'-TCGGGCGCCAAACG-3') and reverse primers (5'-TGCTATACTGGCCTCCAAATGG-3'), $100 \mathrm{nM}$ DIGR2 probe (CCAGCGCCTTCC), $400 \mathrm{nM}$ of DIGR2 forward (5'- CAACCAGAGGCAGGTTTGAGTAC -3') and reverse primers (5'- CCCACAGTGGGCCTACAAGA-3'), $100 \mathrm{nM}$ of actin probe (ACCACAGCCGAGAGG), $400 \mathrm{nM}$ of actin forward (5'CAGAGCGTGGCTACTCCTTCA-3') and reverse primers (5'TCCTTGATGTCACGCACGAT- $3^{\prime}$ ), and $12.5 \mu \mathrm{L}$ of Taqman PCR Master Mix (Applied Biosystem). The 50 cycles of the two steps PCR program consisted of initial polymerase activation for $3 \mathrm{~min}$ at $95{ }^{\circ} \mathrm{C}$ followed by denaturing at $95^{\circ} \mathrm{C}$ for $15 \mathrm{~s}$, and annealing/extension at $60{ }^{\circ} \mathrm{C}$ for $45 \mathrm{~s}$, in which fluorescent signal was detected.

For every time point/treatment five specimens were used and each cDNA sample was run in triplicate together with negative controls.

To obtain sample quantification the $R Q=2^{-\Delta \Delta C t}$ method was used and the relative changes in gene expression analyzed as described in the Applied Biosystem Use Bulletin N.2 (P/N 4303859). For the $\mathrm{Ct}$ calculation to be valid, the amplification efficiencies of the target and the reference gene must be approximately equal. To assess whether amplicons have the same efficiency, a sensitive method was used for checking how $\mathrm{Ct}$ varies with template dilution. Serial dilutions $(1,0.5$, $0.2,0.1,0.005,0.002,0.001)$ of cDNA were amplified by real-time PCR using the target and the housekeeping gene specific primers and the Ct, i.e., $\mathrm{CT}_{\text {(DIGR1 or DIGR2) }}^{-} \mathrm{CT}_{\text {(Actina) }}$, was calculated, in 3 replicates, for each cDNA dilution. Data were analyzed using the linear regression analysis. The amount of DIGR1 and DIGR2 transcripts was normalized with actin to compensate for variations in the amount of RNA. Relative DIGR1 and DIGR2 expressions were determined by dividing the normalized value of DIGR1 and DIGR2 by the normalized value obtained from the untreated tissue.

\subsection{Sequence comparison}

A BLAST search was performed for comparing sequences. Multiple alignments were accomplished with the Clustal W program (Thompson et al., 1994), and similarity and identity percent values were recorded.

\subsection{Tissue homogenate supernatant (THS) preparation}

Tissue samples were crushed in liquid nitrogen, and kept in ice for $1 \mathrm{~h}$ with $1 \mathrm{~mL}$ of lysis buffer (RIPA: $0.5 \%$ sodium deoxycholate minimum 97\%; $1 \%$ NP40; $0.1 \%$ SDS with PBS-T $\left(\mathrm{Na}_{2} \mathrm{HPO}_{4} 1 \mathrm{M}\right.$, $\mathrm{NaH}_{2} \mathrm{PO}_{4} 1 \mathrm{M}, \mathrm{NaCl} 1.5 \mathrm{M}, 0.1 \%$ Tween 20) supplemented with a protease inhibitor cocktail (pepstatin A, E-64, bestatin, leupeptin, aprotinin, and AEBSF) diluted 1:200 (lysis buffer). Then the samples were centrifuged at $15,000 \times \mathrm{g}$ for $30 \mathrm{~min}$ at $4{ }^{\circ} \mathrm{C}$, the supernatants were collected, dialyzed against $50 \mathrm{mM}$ Trizma base (Tris[hydroxymethyl] aminomethane) Sigma-Aldrich, pH 7.5, and the total protein content was determined by using the method of Bradford (1976).

\subsection{SDS-PAGE and Western blot}

SDS-PAGE (7.5\%) under reducing conditions was performed according to the method of Laemmli (1970), and samples, adjusted to $25 \mu \mathrm{g}$ protein content, were analyzed. The protein pattern of THS, was transferred to a nitrocellulose membrane by using a semidry transfer apparatus (BioRad) and blocked with $5 \%$ bovine serum 
albumin (BSA, Sigma-Aldrich) in TBS-T (20 mM Trizma base pH 7.5, $300 \mathrm{mM} \mathrm{NaCl}, 0.1 \%(\mathrm{v} / \mathrm{v}$ ) Tween 20 with $0.02 \%$ sodium azide) for $1 \mathrm{~h}$ at room temperature (r.t.).

To identify DIGR1, the membrane was incubated with a specific antiDIGR1 antiserum (1:3000 dilution, 3 h at r.t.), washed with TBS-T (three times for $5 \mathrm{~min}$ ), incubated with alkaline phosphatase-conjugated goat anti-rabbit IgG (Sigma-Aldrich, 1:10000 for $1 \mathrm{~h}$ at r.t.), and washed with TBS-T (three times for $5 \mathrm{~min}$ ). The membrane was incubated with 5bromo-4-chloro-3-indolyl phosphate/nitro blue tetrazolium liquid substrate system (BCIP/NBT Sigma-Aldrich). To check for antibody specificity, the anti-DIGR1 antiserum was substituted with preimmune rabbit IgG at a suitable dilution. To check for unspecific cross-reaction of the secondary antibody, the primary antibody was not added.

The specific anti-DIGR1 antibody had been previously prepared and already used for DIGR1 immunohistochemical identification studies as reported by Vazzana et al. (2008). In brief, anti-DlGR1 polyclonal antibody was raised in rabbit by using a peptide as antigen corresponding to the hydrophilic sequence located in the N-terminal region (transcriptional activation domain) of DIGR1 (residues from 85 to 98: LEDHESRGLTRDQK). The peptide sequence was selected (by antigen-prediction program) and synthesized by Sigma Genosys (UK).

The integrated density value (IDV) of immunoblots was determined using AlphaImager ${ }^{\mathrm{TM}}$ software.

\subsection{Statistical analysis}

The experiments were performed using 5 specimens for each time point and the results were expressed as a mean value $\pm S D$. The data were compared using the analysis of variance (ANOVA). Homogeneity of variances was performed using Cochran's test prior to the ANOVA analysis. Whenever necessary the data were log-transformed. Posthoc comparisons were made using Student's $t$ test and the significant level was set at $p<0.05$; the analysis was performed with Statistica 6.0 (StatSoft, Tulsa, OK, USA). Linkage between plasma cortisol levels and enhanced GRs expression was checked by correlation matrices.

Since the values from the untreated individuals, recorded at each time point (5 specimens), did not show any significant difference, data from group I and group II were compared to the average value resulting from 15 untreated specimens. On the other hand, data from cortisol-treated fish were compared to control (vehicle-treated) specimens.

\section{Results}

\subsection{Comparison between DIGR1, DIGR2 and HbGR1-2 deduced aminoacid sequences}

A BLAST search showed 61\% sequence identity (I) and 70\% sequence similarity (S) between DIGR1 and DIGR2. Domains comparison disclosed 84\% I and 85\% S between the DNA-binding domains, $47 \%$ I and $62 \% \mathrm{~S}$ between the nuclear localization domains, and $88 \% \mathrm{I}$ and $95 \% \mathrm{~S}$ between the hormone-binding domains, whereas a low similarity was found between the transcriptional activation domains (29\% I, 45\% S).

Higher I and S values were recorded between sea bass DIGR1 and HbGR1 (72\% I, 78\% S) as well as between DIGR2 and HbGR2. In particular, 69\% I 73\% S were between DIGR2 and HbGR2b, and similar values were between DIGR2 and HbGR2a (68\% I, 72\% S).

\subsection{Cortisol and stress-associated signals}

After vehicle inoculation, a significant increase of endogenous cortisol was recorded in the plasma samples from the sham fish (group I), sampled at $3 \mathrm{~h}(p<0.05)$ and $24 \mathrm{~h}(p<0.001)$ post inoculation (p.i.) compared to untreated fish ( $80.5 \mathrm{ng} \mathrm{mL}^{-1}$ ) (Fig. 1A). At these time points after intraperitoneal cortisol implant (group II), the plasma hormone level was found to be further higher $\left(590.2 \mathrm{ng} \mathrm{mL}^{-1}\right)$ than the untreated fish $(p<0.001)$ and the sham fish (at $3 \mathrm{~h}, p<0.01$; at $24 \mathrm{~h}$ $p<0.05$ ).

Glucose (Fig. 1B), lactate (Fig. 1C) and osmolarity (Fig. 1D) levels were found to be significantly higher in the plasma of both sham and cortisol-treated fish (groups I, II). Significant differences were between glucose, lactate and osmolarity levels of sham and cortisoltreated fish. Glucose was significantly higher at $24 \mathrm{~h}$, lactate at 1 week and osmolarity at 3 and $24 \mathrm{~h}$. The plasma values recorded from the 15 untreated specimens did not present any significant variation even when fish were sampled at $3 \mathrm{~h}, 24 \mathrm{~h}$ and 1 week time points after the experiment was started (Fig. 1A, B, C, D).

At 1 week p.i., cortisol, glucose and osmolarity plasma levels of control and cortisol-treated fish appeared to be decreased up to those of the untreated specimens.

3.3. DIGR1 and DIGR2 mRNAs are differentially expressed in the head kidney after cortisol administration

Real-time PCR analysis revealed that head kidney DIGR1 and DIGR2 genes were upregulated by high plasma hormone levels due to the exogeneous cortisol stimulation (group II, Fig. 2A, B). The gene expression was analyzed at $3 \mathrm{~h}, 24 \mathrm{~h}$ and 1 week p.i. in five specimens from each group. The cortisol treatment enhanced the expression of both DIGR1 and DIGR2 genes that reached the highest levels at $24 \mathrm{~h}$ $(p<0.001, p<0.01)$ (Fig. 2A, B). While the DIGR1 gene expression (Fig. 2A) increased significantly at $24 \mathrm{~h}$ and at 1 week, the DIGR2 gene expression (Fig. 2B) increased significantly $(p<0.05)$ at $3 \mathrm{~h}$ and reached the untreated values at 1 week. Until the end of the experimentation, sham fish presented no significant variation in the expression of DIGR1 gene (Fig. 2A), while a significant $(p<0.05)$ increase in the DIGR2 gene expression was found in the head kidney from sham fish at $3 \mathrm{~h}$ and 1 week p.i (Fig. 2B).

Moreover, significant differences $(p<0.01)$ between the expressions of DIGR1 and DIGR2 genes were found at $24 \mathrm{~h}$ and 1 week post inoculation with cortisol.

Statistical analysis disclosed that there was a correlation $\left(R^{2}=0.49\right)$ between enhanced DIGR1 gene expression and high plasma cortisol levels recorded at $24 \mathrm{~h}$ (Figs. $1 \mathrm{~A}$ and 2A). Such a correlation was not found between the cortisol level and the DIGR2 gene expression.

\subsection{DIGR1 protein abundance in the head kidney tissue}

Since anti-DIGR1 specific antibodies were available, an immunoblotting analysis was carried out. As shown in Fig. 3, the head kidney homogenate preparations from sham fish (group I) presented a significantly lowered band density for each time points. The lowest IDV were found in the control samples (group I) both at $24 \mathrm{~h}$ and 1 week $(p<0.001)$ (Fig. 3).

\section{Discussion}

As predicted by previous reports (Greenwood et al., 2003; Stolte et al., 2006) on GR molecular phylogenesis, teleost and nonteleost GRs form distinct branches. GR gene duplicate copies (DIGR1 and DIGR2) that have been found in sea bass (Vizzini et al., 2007; Terova et al., 2005) are in accordance to the GR gene duplication within the teleost lineage. We compared the deduced amino acid sequences of $D$. labrax (Perciformes, Moronidae) DIGR1 (Vizzini et al., 2007) and DIGR2 (indicated as GR by Terova et al., 2005), and both were compared to HbGR1, HbGR2 $a$ and HbGR2 $b$ isoforms of $H$. burtoni (Perciformes, Cichlidae) (Greenwood et al., 2003).

As shown by an alignment of the predicted amino acid sequences, the DIGR duplicate copies have highly conserved aminoacid sequences in C-region, in particularly the DNA-binding domain and 
A

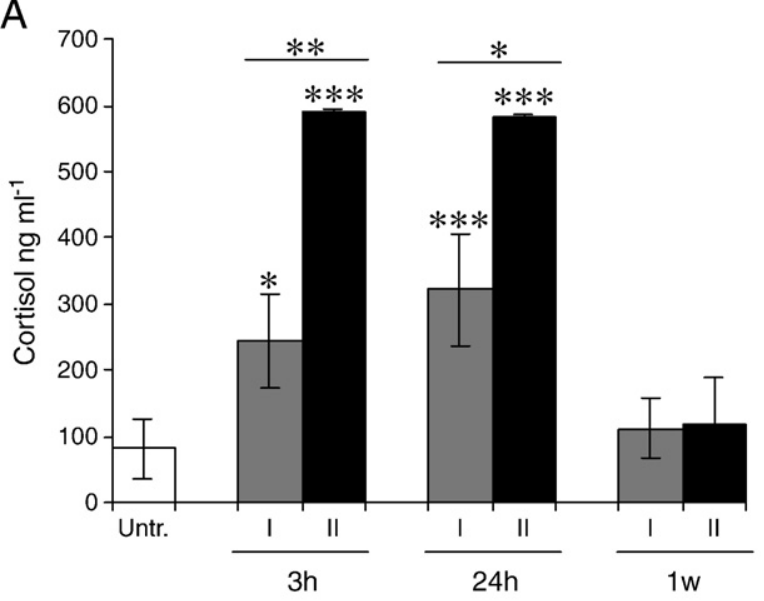

C

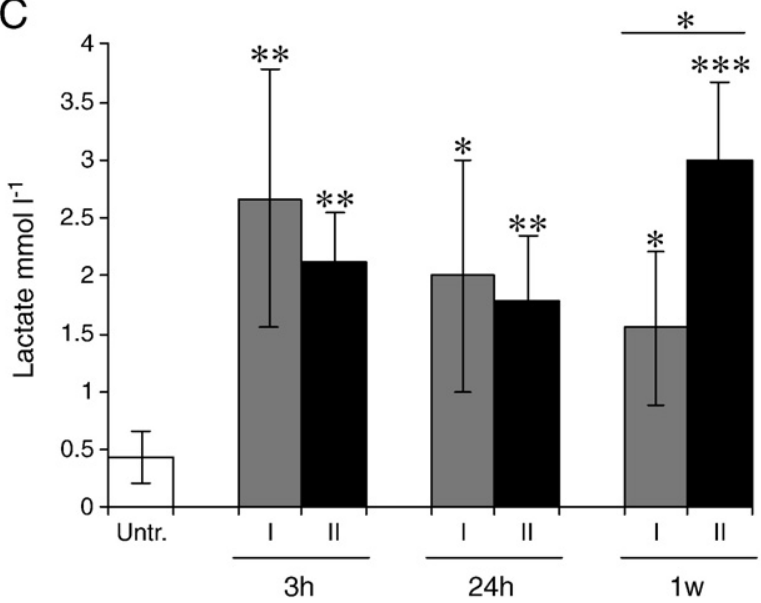

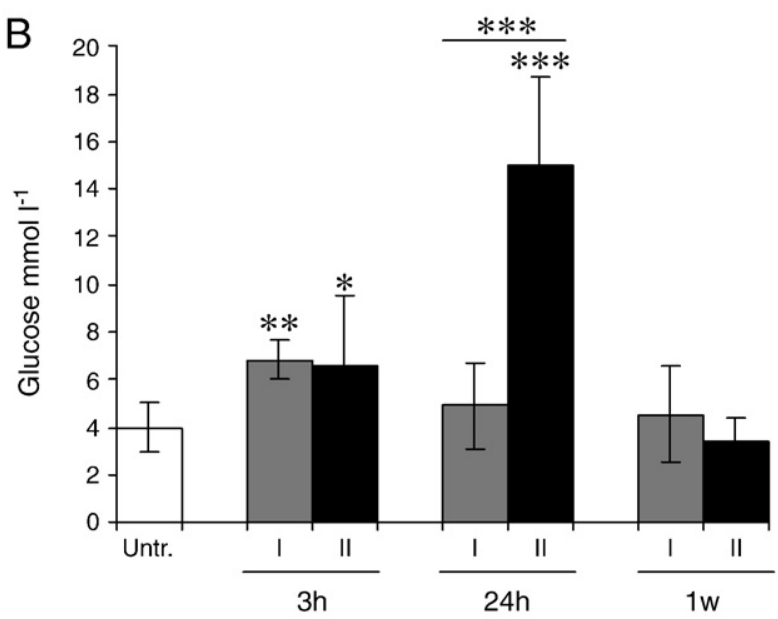

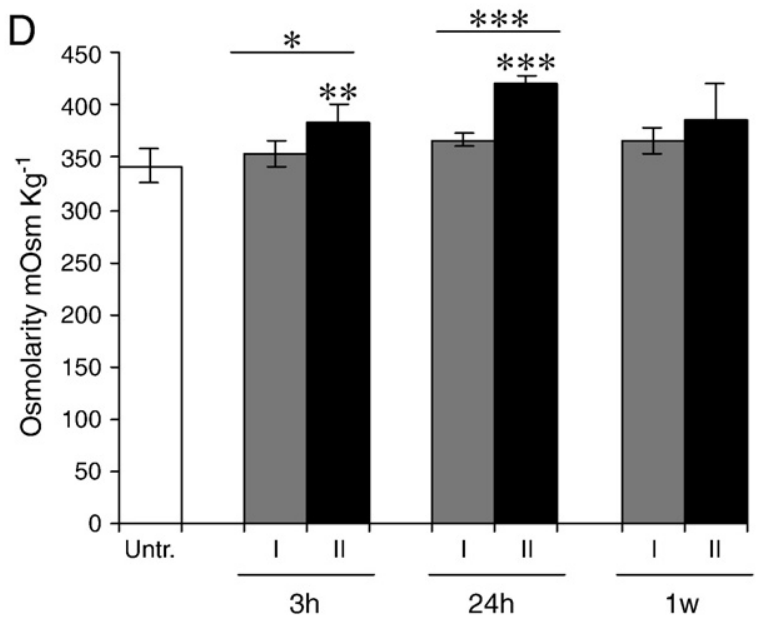

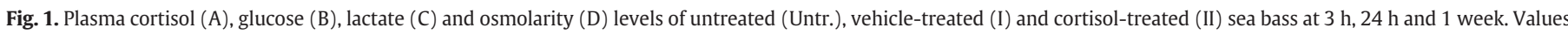

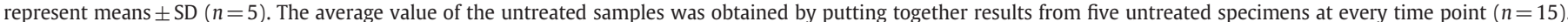

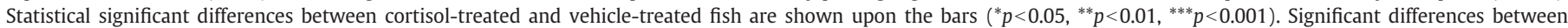
untreated and treated fish (I, II) are also indicated.

the hormone-binding domain are the best conserved ( $84 \% \mathrm{I}, 85 \% \mathrm{~S}$ and $88 \% \mathrm{I}, 95 \% \mathrm{~S}$ ), whereas a lower identity is shared by the nuclear localization domains (47\% I and $62 \% \mathrm{~S}$ ). In N-region the transcriptional activation domain of the two sequences presents the highest diversity (29\% I and $45 \%$ S). Nuclear localization and transcriptional activation domain differences could be related to a differential expression of the duplicate genes regulated by the same hormone. A similar conclusion has been reported by Greenwood et al. (2003) on the domains of HbGR1 and HbGR2.

Compared to other fish species (Stolte et al., 2006), DlGR2 gene shows a 27-nucleotide insert that encodes nine additional aminoacids (WRARQNTDG). This sequence is remarkably conserved among teleostean fish (Stolte et al., 2006). Although Stolte et al. (2006) proposed to name GR1 the gene containing the insert and GR2 the duplicate form, to avoid confusion with our previous papers we named "DIGR1" (Vizzini et al., 2007) the GR that does not present the insert, and "DIGR2" the GR (Terova et al., 2005) that contains the insert

The DIGR1, DIGR2, HbGR1 and HbGR2 amino acid sequence alignments show that the DIGR1 is more similar to the HbGR1 (72\% I$78 \% \mathrm{~S}$ ) than to the DIGR2 (70\% I-61\% S). The DIGR2 is similar to the HbGR2, mainly to the isoform $b$ that contains the insert.

According to Stolte et al. (2006), differences in receptor protein function could be indicated by differential expression of the duplicate DIGR genes.

It is well documented that in fish, cortisol is the major stressrelated hormone, and treatment with exogeneous cortisol mimics stress effects and exerts, in distinct species, differential GR genes regulation (Vijayan et al., 2003; Sathiyaa and Vijayan, 2003; Takahashi et al., 2006). In cortisol-treated sea bass, plasmatic parameters supported that stress conditions had been reached. According to previous papers on fish population density, glucose, lactate and osmolarity levels were enhanced (Mommsen et al., 1999; Milligan and Girard, 1993; Vazzana et al., 2002). High values, including endogeneous cortisol level, found in the plasma of sham fish indicated that the inoculation procedure caused a moderate stressing effect as compared to the lower levels recorded in the plasma of the untreated fish. The further increase in stress indicators levels, due to the exogeneous cortisol, disclosed the effects of the hormone. It is noteworthy that no variations were observed in the untreated fish even when assayed at different time points of the experimental schedule. However the average cortisol level $\left(80.5 \mathrm{ng} \mathrm{mL}^{-1}\right)$ of the untreated specimens examined in the present study was higher than that $\left(10 \pm 8 \mathrm{ng} \mathrm{mL}^{-1}\right)$ previously reported by Vazzana et al. (2002). Such a difference could be due to different environmental conditions and population density between fish from distinct farms. Furthermore, in the previous study, control fish were maintained in $400 \mathrm{~m}^{3}$ farm tanks whereas, in the present study, $0.5 \mathrm{~m}^{3}$ aquarium tanks were used, therefore environmental conditions cannot be straightly compared. The question arises whether the enhanced plasma cortisol differentially modulates the expression of DIGR genes. In rainbow trout, concentrations of cortisol required to induce activation of downstream genes is significantly different between the duplicate 

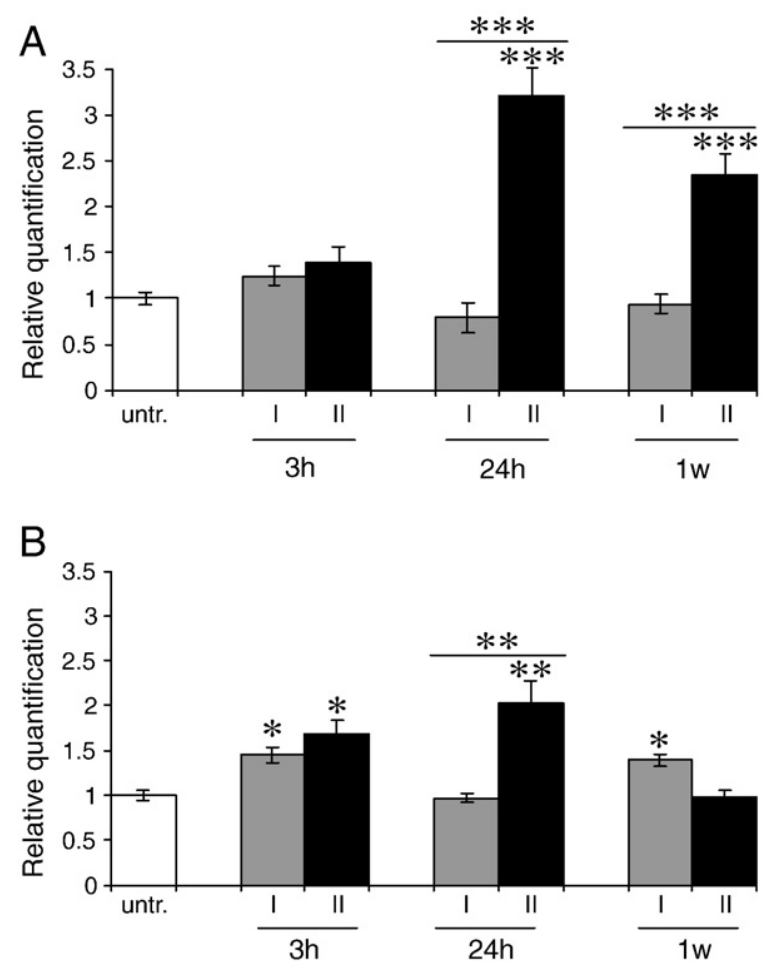

Fig. 2. Effect of cortisol on glucocorticoid receptors DIGR1 (A) and DIGR2 (B) mRNA abundance in the sea bass head kidney of untreated (Untr.), vehicle-treated (I) and cortisol-treated fish (II) at $3 \mathrm{~h}, 24 \mathrm{~h}$, and 1 week. Values represent means $\pm \mathrm{SD}(n=5)$ calculated by assaying untreated and treated (I and II) fish at every time point. Statistical significant differences between cortisol-treated and vehicle-treated fish are shown upon the bars $\left({ }^{*} p<0.05,{ }^{* *} p<0.01,{ }^{* * *} p<0.001\right)$. Significant differences between treated fish (I, II) and untreated specimens are also indicated.

GRs (Bury et al., 2003). In sea bass liver, high plasma cortisol levels due to a high rearing density stress, decreased the DIGR2 expression (Terova et al., 2005). We examined the sea bass head kidney, that is the functional equivalent of the adrenal gland, but it also is the major hemopoietic organ (erythropoiesis, granulopoiesis, and lymphopoiesis) (Kobayashi et al., 2006) involved in fish innate and adaptive immune responses (Rombout et al., 2005). Both GR genes are expressed in the head kidney and they can be modulated by high
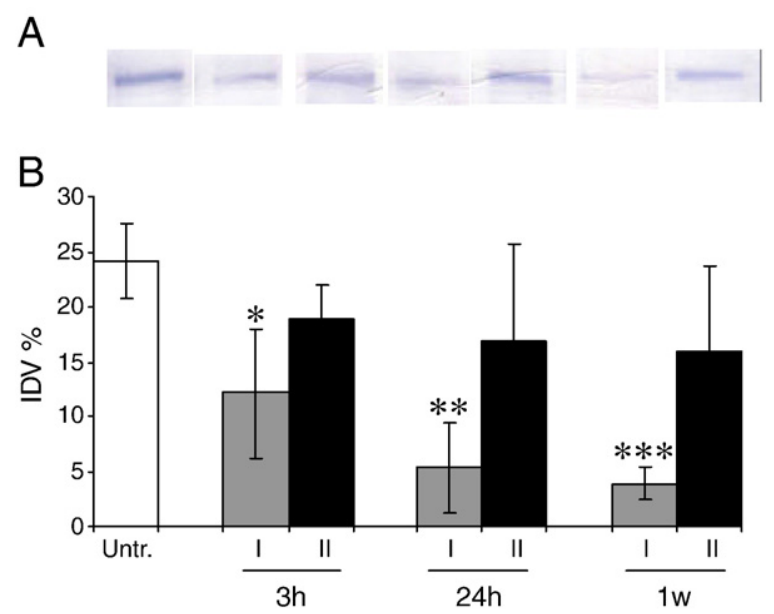

Fig. 3. Sea bass head kidney homogenate supernatant Western blot analysis with antiDIGR1 antibodies. (A) A representative western blot; (B) integrated optical density values (IDV) of the protein bands. Untreated (Untr.), vehicle-treated (I) and cortisoltreated (II) fish. Values represent means $\pm S D(n=5)$ calculated by assaying untreated, and treated (I and II) fish at every time point. Significant differences $\left({ }^{*} p<0.05\right.$, ${ }^{* *} p<0.01,{ }^{* * *} p<0.001$ ) between treated (I, II) and untreated specimens are indicated. plasma cortisol displaying a time-course profile. However, although both the DIGR-mRNAs were significantly increased at $24 \mathrm{~h}$ p.i., the DIGR1 gene expression was mainly enhanced reaching the highest level. In addition, when (at one week) the expression of both GR genes decreased, the DIGR1 gene expression maintained a high level. The correlation analysis supports that plasma cortisol level and head kidney DIGR1 gene expression are correlated. Since macrophages and neutrophils, components of the head kidney white pulp (Vazzana et al., 2008) and peritoneal cavity, express DIGR1 (Vizzini et al., 2007), a role of this GR on cortisol immunomodulation may be suggested. A similar result has been reported on the gene expression of two functionally distinct rainbow trout GR genes: RtGR $2 b$ gene requires a lower level of cortisol than the RtGR1 $a$ gene to induce transactivation (Bury et al., 2003).

It is of interest that the DIGR1 protein, identified in the head kidney homogenate supernatant by specific antibody and analyzed by densitometry, appears to be mainly lowered in sham fish at $24 \mathrm{~h}$ and at 1 week after the vehicle inoculation. According to Wallace and Cidlowski (2001), the possibility exists that the injected medium (vehicle) does not activate the DIGR1 gene transcription whereas the GR protein could be diminished as an effect of a proteasoma-mediated degradation due to the physiologically enhanced plasma cortisol (250-300 $\mathrm{ng} \mathrm{mL}^{-1}$ plasma cortisol). Such a DIGR1 protein diminution could be compensated by the transcription activity enhanced by exceeding plasma cortisol. This is supported by the correlation between plasma hormone level and real-time PCR analysis. In the cortisol-treated specimens, the production of DIGR1 protein appears to be increased but a constant level was found at any time point, like that of untreated specimens.

Our results allow us to speculate that a differential expression of the two DIGR genes could reflect the regulation of tissue specific genes by different types of glucocorticoid-sensitive promoters. In addition, according to the competitive effect of a GR blocker (RU486) on the activity of cortisol-treated peritoneal phagocytes (Vizzini et al., 2007), an immunomodulatory role of the differentially expressed head kidney DIGR1 may be suggested.

\section{References}

Barton, B.A., Morgan, J.D., Vijayan, M.M., 2002. Physiological and condition-related indicators of environmental stress in fish. In: Adams, S.M. (Ed.), Biological Indicators of Aquatic Ecosystem Health. American Fisheries Society, Bethesda, MD, pp. 111-148.

Beato, M., Chavez, S., Truss, M., 1996. Transcriptional regulation by steroid hormones. Steroids 61, 240-251.

Bradford, M.M., 1976. A rapid and sensitive method for the quantitation of microgram quantities of proteins utilizing the principles of protein-dye binding. Anal. Biochem. 72, 248-254.

Bury, N.R., Sturm, A., 2007. Evolution of the corticosteroid receptor signalling pathway in fish. Gen. Comp. Endocrinol. 153, 47-56.

Bury, N.R., Sturm, A., Le Rouzic, P., Lethimonier, C., Ducouret, B., Guiguen, Y., RobinsonRechavi, M., Laudet, V., Rafestin-Oblin, M.E., Prunet, P., 2003. Evidence for two distinct functional glucocorticoid receptors in teleost fish. J. Mol. Endocrinol. 31, $141-156$.

Charmandari, E., Tsigos, C., Chrousos, G., 2005. Endocrinology of the stress response. Ann. Rev. Physiol. 67, 259-284.

Ducouret, B., Tujague, M., Ashraf, J., Mouchel, N., Servel, N., Valotaire, Y., Thompson, E.B., 1995. Cloning of a teleost fish glucocorticoid receptor shows that it contains a deoxyribonucleic acidbinding domain different from that of mammals. Endocrinology 136, 3774-3783.

Elenkov, I.J., 2004. Glucocorticoids and the Th1/Th2 balance. Ann. N.Y. Acad. Sci. 1024, $138-146$.

Greenwood, A.K., Butler, P.C., White, R.B., DeMarco, U., Pearce, D., Fernald, R.D., 2003. Multiple corticosteroid receptors in a teleost fish: distinct sequences, expression patterns, and transcriptional activities. Endocrinology 144, 4226-4236.

Kobayashi, I., Sekiya, M., Moritomo, T., Ototake, M., Nakanishi, T., 2006. Demonstration of hematopoietic stem cells in ginbuna carp (Carassius auratus langsdorfii) kidney. Dev. Comp. Immunol. 30, 1034-1046.

Laemmli, U.K., 1970. Cleavage of structural proteins during the assembly of the head of bacteriophage T4. Nature 227, 680-685.

Milligan, C.L., Girard, S.S., 1993. Lactate metabolism in rainbow trout. J. Exp. Biol. 180, 175-193.

Mommsen, T.P., Vijayan, M.M., Moon, T.W., 1999. Cortisol in teleosts: dynamics, mechanisms of action, and metabolic regulation. Rev. Fish Biol. Fish. 9, 211-268. 
Mugnier, C., Fostier, A., Guezou, S., Gaignon, J.L., Quemener, L., 1998. Effect of some repetitive factors on turbot stress response. Aquacult. Int. 6, 33-45.

Pottinger, T.G., 1998. Changes in blood cortisol, glucose and lactate in carp retained in anglers' keepnets. J. Fish Biol. 53, 728-742.

Prunet, P., Sturm, A., Milla, S., 2006. Multiple corticosteroid receptors in fish: from old ideas to new concepts. Gen. Comp. Endocrinol. 147, 17-23.

Rombout, J.H.W.M., Huttenhuis, H.B.T., Picchietti, S., Scapigliati, G., 2005. Phylogeny and ontogeny of fish leucocytes. Fish Shellfish Immunol. 19, 441-455.

Sapolsky, R.M., Romero, L.M., Munck, A.U., 2000. How do glucocorticoids influence stress responses? Integrating permissive, suppressive, stimulatory, and preparative actions. Endocr. Rev. 21, 55-89.

Sathiyaa, R., Vijayan, M.M., 2003. Autoregulation of glucocorticoid receptor by cortisol in rainbow trout hepatocytes. Am. J. Physiol. Cell Physiol. 284, C1508-C1515.

Stolte, E.H., van Kemenade, B.M., Savelkoul, H.F., Flik, G., 2006. Evolution of glucocorticoid receptors with different glucocorticoid sensitivity. J. Endocrinol. 190, 17-28.

Takahashi, H., Sakamoto, T., Hyodo, S., Shepherd, B.S., Kaneko, T., Grau, E.G., 2006. Expression of glucocorticoid receptor in the intestine of a euryhaline teleost, the Mozambique tilapia (Oreochromis mossambicus): effect of seawater exposure and cortisol treatment. Life Sci. 78, 2329-2335.

Terova, G., Gornati, R., Rimoldi, S., Bernardini, G., Saroglia, M., 2005. Quantification of a glucocorticoid receptor in sea bass (Dicentrarchus labrax, L.) reared at hight stocking density. Gene 357, 144-151.
Thompson, J.D., Higgins, D.G., Gibson, T.J., 1994. Clustal W: improving the sensitivity of progressive multiple sequence alignment through sequence weighting, positionspecic gap penalties and weight matrix choice. Nucleic Acids Res. 22, 4673-4680.

Vazzana, M., Cammarata, M., Parrinello, N., 2002. Confinement stress in sea bass (Dicentrarchus labrax) depresses peritoneal leukocyte cytotoxicity. Aquaculture 210, 231-243.

Vazzana, M., Vizzini, A., Salerno, G., Di Bella, M.L., Celi, M., Parrinello, N., 2008. Expression of a glucocorticoid receptor (DIGR1) in several tissues of the teleost fish Dicentrarchus labrax. Tissue Cell 40, 89-94.

Vijayan, M.M., Pereira, C.E., Grau, G., Iwama, G.K., 1997. Metabolic responses associated with confinement stress in tilapia: the role of cortisol. Comp. Biochem. Physiol. C $116,89-95$.

Vijayan, M.M., Raptis, S., Sathiyaa, R., 2003. Cortisol treatment affects glucocorticoid receptor and glucocorticoid-responsive genes in the liver of rainbow trout. Gen. Comp. Endocrinol. 132, 256-263.

Vizzini, A., Vazzana, M., Cammarata, M., Parrinello, N., 2007. Peritoneal cavity phagocytes from the teleost sea bass express a glucocorticoid receptor (cloned and sequenced) involved in genomic modulation of the in vitro chemiluminescence response to zymosan. Gen. Comp. Endocrinol. 150, 114-123.

Wallace, A.D., Cidlowski, J.A., 2001. Proteasome-mediated glucocorticoid receptor degradation restricts transcriptional signaling by glucocorticoids. J. Biol. Chem. 276 42714-42721.

Wendelaar Bonga, S.E., 1997. The stress response in fish. Physiol. Rev. 77, 591-625. 